\title{
O papel das redes criadas pelas operadoras hegemônicas na escolha do destino das viagens - de Londrina para o Brasil
}

\author{
Juliana Grigoli Pelarim* \\ Maria del Carmen Matilde Huertas Calvente**
}

\section{Resumo}

Esta pesquisa buscou analisar o papel das agências de viagens no processo de turistificação que ocorre no território brasileiro, tendo como embasamento teórico o conceito de território-rede e utilizando-se de aplicação de questionários em empresas do município de Londrina para coleta de dados. Houve uma preocupação, na pesquisa empírica, em responder à questão inicial acerca da influência exercida por parte das operadoras de turismo em relação à divulgação e consumo dos lugares. Por meio de aplicação de questionários nas agências de viagens do município de Londrina, que soma um total de 72 estabelecimentos, definiu-se por amostragem 20 agências nas quais se coletaram dados para análise da apreensão do fenômeno turístico com base na perspectiva dos agentes de viagens.

Palavras-chave: Redes; Lugares; Londrina; Operadoras de Turismo; Pacotes Turísticos.

** Mestre em Geografia pela Universidade Estadual de Londrina (julianagrigoli@hotmail.com).

**** Docente da Universidade Estadual de Londrina (calvente@uel.br).

Geosul, Florianópolis, v. 30, n. 59, p 95-116, jan./jun. 2015 
PELARIM, J.G. \& CALVENTE, M.C.M.H. O papel das redes criadas pelas...

The role of the networks created by the hegemonic operators in the choise of the travel destiny - from Londrina to Brasil

\begin{abstract}
This research aimed to analyze the role of the travel agencies in the touristification process that occurs in Brazilian territory, based on the concept of territory-network and using, for data collection, the application of questionnaires in enterprises from the city of Londrina. At the empirical research, there was a concern in answer the initial question, about the influence exercised by the tourism operators in relation to the divulgation and consumes of the places. By the application of questionnaires at the tourism operators from Londrina, 72 in totally, it was defined by sample 20 agencies in which dates were collected for analyze the apprehension of the touristic phenomenon based on the perspective of the travelers agents.
\end{abstract}

Key words: Networks; Place; Londrina; Tourism Operators; Tourist Packages.

\title{
Introdução
}

O poder exercido pelos veículos de comunicação opera papel indiscutível no mundo das viagens, amplamente articulado por diversos meios que vendem os lugares. A dinâmica da atividade turística é composta por vários agentes produtores e as relações que são estabelecidas entre estes formam uma rede que compõe as especificidades deste fenômeno, o que não significa dizer, no entanto, que estes agentes atuem em equidade de condições ou de influências.

Tendo como embasamento teórico o conceito de territóriorede (DIAS, 1995; SAQUET, 2009) e por meio de entrevistas nas agências de viagens do município de Londrina, coletaram-se informações para a análise da apreensão do fenômeno turístico com base na perspectiva do título deste artigo. 
PELARIM, J.G. \& CALVENTE, M.C.M.H. O papel das redes criadas pelas...

No caso específico do recorte espacial onde a pesquisa empírica foi realizada, pôde-se apreender que embora tenham sido encontrados elementos que seguem a lógica impositiva do mercado, encontraram-se também outras possibilidades, que serão discutidas no texto a seguir.

\section{As redes criadas para as vendas dos pacotes turísticos}

A organização de viagens por meio de um intermediário entre os prestadores dos serviços efetivamente utilizados nos destinos e os viajantes é um processo recente, e assim há um baixo número de trabalhos de pesquisa com abordagem na temática proposta. Pondera-se aqui sobre a importância das agências e operadoras, já que suas atribuições estão tanto ligadas à produção como à distribuição do turismo e suas atividades encontram-se nos núcleos emissores e nos núcleos receptores. Atuam como intermediadoras entre os turistas e os prestadores de serviços, servindo a estes na ampliação da divulgação de seus serviços em diversos lugares e àqueles na facilitação de organizar uma viagem a um lugar desconhecido.

Segundo Rejowski (2004), no Brasil registra-se que a primeira agência de viagens, Agência Geral de Turismo, deu início às suas atividades em 1943 na cidade de São Paulo. Os serviços prestados, ainda incipientes, consistiam na organização de excursões de ônibus, inaugurando posteriormente uma viagem aérea para o carnaval no Rio de Janeiro. Ressalta-se que neste período a aviação comercial brasileira não era desenvolvida e não existiam redes hoteleiras. Informa o autor que entre os anos de 1947 e 1950 começaram a crescer o número de agências de viagens no Brasil.

O ano de 1953 foi marco da institucionalização de órgãos representantes e de regulamentação da atividade, com a fundação, no Rio de Janeiro, da ABT - Associação Brasileira de Turismo. Esta, porém, não prosperou. No entanto, no mesmo ano e na mesma cidade, estabelece-se a fundação da ABAV - Associação Brasileira de Viagens - valendo-se da reunião de representantes de 
PELARIM, J.G. \& CALVENTE, M.C.M.H. O papel das redes criadas pelas...

15 agências de viagens. Neste ano existiam no Rio de Janeiro 74 agências de viagens. Paralelamente ao movimento no Rio de Janeiro, emergia também em São Paulo a organização dos agentes, neste período ainda não formalmente regulamentados. A formação da Delegacia de São Paulo da ABAV data de 1959 (ABAV, 2004).

Para se tratar da comercialização dos produtos turísticos por intermédio das agências, fazem-se necessárias algumas considerações básicas acerca dos termos utilizados. A legislação brasileira, pelo Decreto ${ }^{\circ} 84.934$, de 21 de julho de 1980, trata das atividades e serviços das agências de turismo, regulamentando o seu registro e funcionamento assim como outras providências (BRASIL, 1980). Entende-se por agência de turismo a empresa comercial que se dedica a prestar serviços relativos às necessidades de quem deseje viajar, desde a informação até a organização. De acordo com o artigo $2^{\circ}$ do referido decreto, fica definida como atividade privativa destas empresas a prestação de serviços consistentes em:

I - venda comissionada ou intermediação remunerada de passagens individuais ou coletivas, passeios, viagens e excursões; II - intermediação remunerada na reserva de acomodações; III - recepção, transferência e assistência especializadas ao turista ou viajante; IV - operação de viagens e excursões, individuais ou coletivas, compreendendo a organização, contratação e execução de programas, roteiros e itinerários; V - representação de empresas transportadoras, empresas de hospedagem e outras prestadoras de serviços turísticos; VI - divulgação pelos meios adequados, inclusive propaganda e publicidade, dos serviços mencionados nos incisos anteriores (BRASIL, $1980, \mathrm{~s} / \mathrm{p})$.

$\mathrm{O}$ artigo $4^{\circ}$ estabelece que as agências de turismo enquadram-se em duas categorias: I - Agência de Viagens e Turismo que são prestadores de serviços não somente ao cliente direto, mas, sobretudo, direcionam-se às agências de viagens, em viagens nacionais e internacionais. Em caráter privativo, as 
PELARIM, J.G. \& CALVENTE, M.C.M.H. O papel das redes criadas pelas...

agências de viagem e turismo prestam serviços de operação de viagens, de forma individual ou em grupo, organizando, contratando e executando os programas, os roteiros e os itinerários; e II - Agência de Viagens que são prestadores de serviços aos seus clientes dentro do Brasil e nos países limítrofes, quando complementando uma viagem (ATHENIENSE, 2004).

No presente texto, as empresas denominadas como agências de viagens e turismo na legislação serão tratadas, conforme Beni (2001), pelo termo operadoras de turismo, internacionalmente conhecidas como tour operators e agências de viagens. .

A Figura 1 sintetiza as possibilidades de comercialização do produto turístico analisadas pelo MTur, com o chamado canal de comercialização que é formado para a venda dos serviços turísticos. Demonstram-se quatro níveis no processo de comercialização, que vai do nível zero, no qual o contato do prestador de serviço é feito diretamente com o consumidor, isto é, sem nenhuma intermediação nos níveis um, dois e três. Os níveis indicam o número de intermediadores que atuam no processo.

Figura 1: Canais de comercialização do turismo
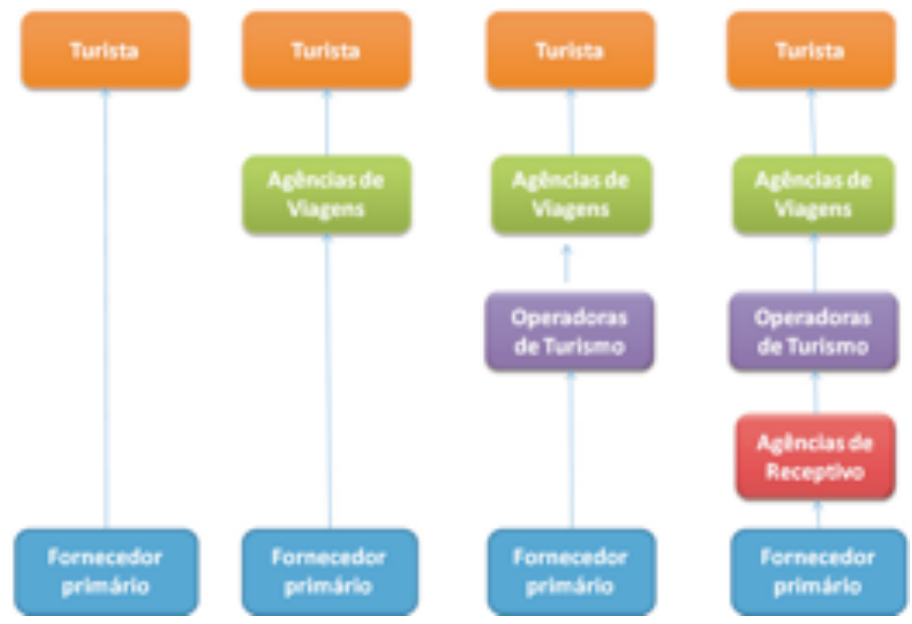

Geosul, v.30, n.59, 2015 
PELARIM, J.G. \& CALVENTE, M.C.M.H. O papel das redes criadas pelas...

Fonte: Brasil, (2010, p. 113)

O modo como o turismo vem sendo atualmente comercializado tem causado influência e subsidiado transformações no mercado turístico. Neste sentido, observa-se que: "As grandes operadoras turísticas e as agências de viagens escolhem os fornecedores de acordo com a qualidade do produto e as vantagens oferecidas, que poderão ser repassadas aos clientes" (BRASIL, 2010, p. 113 - grifo nosso).

Beni (2001, p. 185) ressalta que o aumento no número de intermediários entre o fornecedor primário e o turista reflete em uma diminuição do controle que este tem da distribuição/ comercialização. Para o autor, o papel dos intermediários, como as operadoras de turismo, assume a função do fornecedor primário quando "[...] cria e organiza um tour a partir de insumos de outras empresas".

A Figura 1 demonstra claramente a formação de uma rede. Viabilizada pelo atual processo de desenvolvimento técnico e informacional no qual se vive, esta rede reflete-se diretamente no território, tendo em vista que cada um dos sujeitos envolvidos no processo de viabilizar destinos para a atividade turística imprime no território suas marcas de acordo com suas necessidades. Becker (2001, p. 3) é enfática ao analisar o papel das redes e do marketing na distribuição do produto turístico, considerando-os fundamentais para a estruturação da atividade conforme atualmente se apresenta.

A presença das redes é extremamente importante na viabilização da mercantilização da imagem dos lugares. A mídia tem papel fundamental para o desenvolvimento das estratégias de marketing, elemento central na questão do turismo. O marketing, as redes de informação e de circulação atraem crescente número de consumidores, inserindo-os num circuito de mercado através de "pacotes" diversos.

Como afirma Coriolano (2006), a dinâmica da atividade turística, uma entre as mais recentes no processo de atual de acumulação, imprime no espaço a lógica de reprodução do capital. 
PELARIM, J.G. \& CALVENTE, M.C.M.H. O papel das redes criadas pelas...

Nesta perspectiva, buscou-se, a seguir, apreender o papel das operadoras de turismo e sua influência nas agências de viagens. Tomando por base a pesquisa empírica, tendo como recorte espacial o município de Londrina, foram coletados dados que subsidiam esta análise, os quais foram analisados e expostos na sequência deste trabalho.

\section{Brasil e Londrina: o poder das operadoras hegemônicas}

A parte empírica desta pesquisa foi realizada no município de Londrina. Foram aplicados questionários nas agências de turismo para coleta de dados imprescindíveis para a análise proposta.

Buscou-se analisar, tomando por base os dados coletados, ou seja, os resultados obtidos acerca da percepção dos agentes de viagens, a influência das operadoras de turismo na rede formada pela atividade turística. Entende-se que a densificação das redes permitem, conforme ressalta Dias (1995), simultaneamente a circulação e a comunicação, ao tornar-se um elemento fundamental da atividade turística. Foram utilizadas no texto a seguir nomenclaturas como cliente e produto turístico, por se tratar da visão dos agentes entrevistados, ao que se ressalta ser uma análise pautada na relação basicamente mercadológica que se tem com a atividade turística.

A Tabela 1, a seguir, pertence ao grupo de perguntas sobre a relação da agência com as operadoras; as viagens turísticas organizadas por estas são mais facilmente comercializadas, os pacotes turísticos ofertados atendem as principais necessidades no que se refere ao deslocamento, acomodação e diversão, que são elementos base para organização de uma viagem.

Os pacotes, via de regra, oferecem os mesmos serviços, transporte aéreo para o destino escolhido, transfer (aeroporto hotel - aeroporto), hospedagem conforme a escolha do cliente e normalmente um passeio pela cidade (city tour). A variável mais recorrente apontada como fator de decisão dos agentes em 
PELARIM, J.G. \& CALVENTE, M.C.M.H. O papel das redes criadas pelas...

trabalharem com determinada operadora seria o preço do pacote, fato esperado, visto que como consumidor almeja-se obter o maior benefício pelo menor custo. Fatores como disponibilidade de acesso via internet (Portal), que permitem a consulta online de disponibilidade e de preço dos pacotes, incentivo ao agente (remuneração por bônus) e a fidelização da operadora que se mantêm somente como operadora, ou seja, não entrando na venda direta ao cliente, foram citados como relevantes na escolha.

Tabela 1: Como é feita a escolha da operadora?

\begin{tabular}{crr}
\hline Motivo & $\mathbf{N}^{\mathbf{0}}$ & $\mathbf{\%}$ \\
\hline Preço dos pacotes & 13 & 28 \\
Atendimento & 8 & 17 \\
Visita dos representantes & 6 & 13 \\
Serviço & 5 & 11 \\
Comissão & 4 & 8 \\
Agilidade no atendimento & 4 & 8 \\
Credibilidade & 2 & 4 \\
Outros & 5 & 11 \\
\hline Total & $\mathbf{4 7}$ & $\mathbf{1 0 0}$
\end{tabular}

Respostas múltiplas.

A Tabela 2 nomeia as principais operadoras lembradas pelos entrevistados. Posteriormente, buscou-se apresentá-las de maneira resumida ao leitor.

De acordo com os entrevistados, às vezes ao procurar a agência o viajante já menciona a operadora que tem interesse, fato este, segundo o entrevistado, decorrente do trabalho realizado em relação à marca, que se utiliza de vários meios de comunicação para fixar-se entre os consumidores. Esta afirmativa remete inevitavelmente ao pensamento de Harvey (1992) que aponta para o fato da utilização das imagens dos lugares serem, assim como 
PELARIM, J.G. \& CALVENTE, M.C.M.H. O papel das redes criadas pelas...

outra qualquer, utilizada para a produção e uso temporário. Das três empresas mais citadas, CVC, ABT e FRT, traz-se um breve histórico, com informações obtidas nos sítios das empresas, na tentativa de associarem-se os fatores mencionados como critério para escolha das operadoras mais citadas.

Tabela 2: Com quais operadoras trabalham?

\begin{tabular}{crr}
\hline Nome da operadora citada & \multicolumn{2}{c}{$\mathbf{N}^{\mathbf{0}}$} \\
\hline CVC & 18 & 23 \\
ABT & 15 & 19 \\
FRT & 8 & 10 \\
BRT & 5 & 6 \\
Trend & 5 & 6 \\
MGM & 4 & 5 \\
New Line & 3 & 4 \\
TAM Viagens & 3 & 4 \\
Citadas uma vez (AIT, Azul Viagens, Flot, MG travel, Personal) & 7 & 9 \\
Citadas duas vezes (MAK Tour, Schultz, Visual) & 6 & 8 \\
Operação própria para roteiros rodoviários ou de pesca & 5 & 6 \\
\hline Total & $\mathbf{7 9}$ & $\mathbf{1 0 0}$
\end{tabular}

Data de 1972 a abertura da empresa CVC, cujo nome provém das iniciais de um dos sócios fundadores, autointitulada como maior operadora de turismo da América Latina e primeira no Brasil a realizar fretamentos aéreos, que foi citada por 18 dos agentes de viagens. Entre lojas próprias e franquias está presente hoje em 283 municípios brasileiros, espalhados por todos os estados e distrito federal; desde 1996 atua na venda direta ao consumidor, tornando-se ao mesmo tempo operadora de turismo e agência de viagens, e em 2000 inaugurou a primeira loja virtual 
PELARIM, J.G. \& CALVENTE, M.C.M.H. O papel das redes criadas pelas...

brasileira para compra de viagens. É notório o poder de negociação que esta operadora exerce sobre os fornecedores, refletindo diretamente no preço do pacote final (CVC, 2013).

$\mathrm{O}$ aparecimento da ABT Operadora entre as mais citadas é um fato surpreendente e passível de análise detalhada. Esta empresa surge como resultado da experiência de uma agência de viagens consolidada no mercado londrinense há mais de 25 anos, que resolve então atuar como operadora. A estruturação desta empresa visa proporcionar ao agente de viagens um atendimento diferenciado. Para tanto, investiu-se fortemente em ferramentas de reservas online, para passagens e hotéis, além de qualificação dos profissionais que auxiliam os agentes. Nota-se que o fato da empresa estar entre as três mais citadas, mesmo com tão pouco tempo no mercado, é um reflexo do trabalho diferenciado que têm prestado, visto que o atendimento e a visita de representantes da empresa então entre os fatores mais citados para a escolha da operadora (ABT, 2013).

A FRT Operadora de Turismo, citada por oito entre os 20 entrevistados, também é uma operadora regional, foi fundada em Foz do Iguaçu-PR, está no mercado desde 2001 e nasceu de uma agência de viagens que atua no mercado desde 1979. A operadora destaca entre os seus maiores esforços o investimento no portal online, para reserva e emissão de passagens aéreas, hotéis e serviços, assim como o treinamento dos colaboradores (FRT, 2013).

Sendo considerado um fator surpresa da pesquisa o fato de operadoras locais estarem entre as três mais citadas pelos agentes, considerou-se importante retomar o contato com os entrevistados a fim de apreender qual seria a razão disto. Via de regra, a resposta dos agentes considerava fatores como: pessoalidade no atendimento, disponibilidade para solucionar problemas fora do horário comercial, qualidade no serviço prestado, seja no atendimento para a venda do pacote ou nos serviços prestados durante a viagem, além do fato dos preços das mesmas serem 
PELARIM, J.G. \& CALVENTE, M.C.M.H. O papel das redes criadas pelas...

competitivos se comparados com outras que operam em nível nacional.

A resposta de um dos entrevistados resume a compreensão geral que se obteve: "No passado as operadoras trabalhavam exclusivamente atendendo as agências de viagens, a CVC quebrou esta regra montando lojas de atendimento direto ao cliente; o agente de viagens tomou consciência e passou a priorizar as operadoras que não fazem isto. Além do que, se antes o preço da CVC era imbatível, hoje já não é o que ocorre, outras operadoras são tão competitivas quanto. $\mathrm{O}$ fato de empresas locais estarem no topo do ranking não me surpreende. Temos um contato muito pessoal e a proximidade nos traz, certamente, segurança".

Cabe ainda ressaltar que cinco entre as agências entrevistadas operacionalizam seus próprios pacotes, sendo estes, sobretudo rodoviários e tendo nichos específicos do mercado, como por exemplo: grupos escolares, grupos de terceira idade e grupos de pescaria. Nestes casos, observa-se a redução do canal de comercialização do turismo, já que não envolve a intermediação das operadoras.

Em análise sobre o uso de tecnologias da informação nos canais de distribuição do turismo, Zagheni e Luna (2011) consideram que o desenvolvimento tecnológico possibilitou a diversificação nos canais de atendimento e de entrega dos serviços turísticos. Citado como o meio mais frequente de comunicação, o correio eletrônico dá, segundo os agentes, a ambas as partes a segurança de ter as informações registradas, já que é considerado como um documento. $\mathrm{O}$ uso das ferramentas virtuais não substitui o uso do telefone, que aparece como segunda opção mais utilizada, sendo apontado como ferramenta de rápida consulta, sobretudo para informações de pequenos detalhes visto que o conteúdo das conversas não pode ser registrado. A comunicação feita em tempo real por meio de programas de conversação aparece citada em terceiro lugar, ganhando notoriedade pela eficiência e também por permitirem o registro das informações prestadas. 
PELARIM, J.G. \& CALVENTE, M.C.M.H. O papel das redes criadas pelas...

Urry (1996, p. 83) assinala que "A tecnologia da informação possibilita que vários tipos de rede se estabeleçam entre os consumidores em potencial e as muitas unidades específicas e descentralizadas". As novas tecnologias assumem papel essencial e indispensável para viabilizar a forma de turismo como se conhece hoje.

Analisou-se a apreensão dos agentes sobre o papel exercido pela operadora no que concerne a importância destas em relação a comercialização das viagens. Dado que o contato com os fornecedores é feito pela operadora que agrupa todos os serviços necessários nos chamados pacotes, ou seja, transporte, hospedagem e serviços de transfer, os agentes consideraram esta facilidade como principal característica da operadora. Citadas como as atacadistas do negócio turístico, as operadoras de turismo aparecem como tendo relevante poder de negociação com os fornecedores, o que viabiliza preços mais baixos para os pacotes finais.

Também se buscou analisar questões referentes a relação das agências de viagens com os seus clientes. Muito embora o preço dos pacotes tenha sido anteriormente citado como fator decisivo na escolha das operadoras, no grupo de perguntas que relacionam informações sobre as agências e seus clientes, este aparece citado em terceiro lugar, sendo resposta de apenas quatro dos entrevistados. A internet e os meios de comunicação em geral têm influenciado diretamente no comportamento dos turistas. Segundo os agentes de viagens, antes de buscarem a agência os clientes procuram obter informações e dicas sobre os destinos. A facilidade de pesquisar informações sobre o destino e planejar a viagem por conta própria bastando apenas ter acesso à internet modificou a relação entre o cliente e o agente de viagens, que hoje tem um papel de consultoria valendo-se dos seus conhecimentos e experiências.

Ao definir algumas das características que compõem a denominada atividade turística, Urry a define como o tempo gasto de modo oposto ao do trabalho, uma prática tida como necessária na vida moderna. Em sua análise afirma: 
PELARIM, J.G. \& CALVENTE, M.C.M.H. O papel das redes criadas pelas...

\section{É difícil conceber a natureza do turismo contemporâneo sem ver como tais atividades são literalmente construídas em nossa imaginação pela propaganda e pela mídia, bem como pela competição consciente entre diferentes grupos sociais (URRY, 1996, p. 30).}

Este tipo de ação cuidadosamente arquitetada que permeia a atividade turística atinge muito certamente os objetivos relacionados às vendas, criando nas pessoas o desejo por determinados lugares e tipos de viagens, como os pacotes préformatados. Os pacotes de viagens são compostos dos itens básicos para o deslocamento e permanência no destino. Os chamados préformatados seriam os pacotes padronizados. São ofertados e vendidos em larga escala, tendo os custos reduzidos em relação aos pacotes personalizados (forfait), e sendo, nas palavras dos agentes, muito engessados. Já os pacotes personalizados atendem ao público mais exigente com necessidades mais específicas e que tenham obviamente disponibilidade de pagar mais pelos serviços exclusivos. Os hábitos de comportamento e de consumo da sociedade atual estão associados aos ditames dos interesses do capital, ou seja, há uma tendência de atitudes em série, repetidas como mimetismo comportamental. Gallero (2001, p. 34) escreve:

La globalización uniformizo los instrumentos, los vehículos, los productos de consumo [...] Y también generalizó las formas de realizar el turismo y, lo que es más grave, unificó - pantalla mediante - la utilización dominante del tiempo libre.

Sobre a comunicação entre os agentes e os clientes, apreende-se que as formas de comunicação disponíveis atualmente fundamentam esta relação. A comunicação entre agência e seus clientes depende hoje fundamentalmente dos meios tecnológicos, assim a utilização da internet, seja para troca de correio eletrônico ou recursos de conversas em tempo real, é a primeira a ser citada, seguida do telefone e do contato pessoal. A rede técnica de comunicação tornou-se imprescindível ao negócio turístico, conectando todos os envolvidos nos canais de distribuição da 
PELARIM, J.G. \& CALVENTE, M.C.M.H. O papel das redes criadas pelas...

atividade. Rocha (2006, p. 80) afirma ser o desenvolvimento das redes técnicas, entre elas a turística, responsável pelo desenvolvimento das redes geográficas que constroem o território, e que:

É, pois, na contemporaneidade que a rede informacional se posiciona como aquela cujas inovações se avolumam com maior celeridade. Nesse sentido, as megalópoles e metrópoles são os pontos nodais de maior expressão para a rede. Daí, tanto partem como convergem inovações, comandos que conferem dinamismo ao território, e o turismo vai acirrar este movimento de fluxos entre as redes.

Quando perguntados sobre os comentários que os turistas fazem ao voltar de viagem, mais especificamente sobre as pessoas envolvidas na atividade turística do lugar visitado, é surpreendente a falta de entrosamento entre as partes, conforme a percepção dos agentes de viagens. Majoritariamente as respostas apontam para o não interesse do viajante em estabelecer uma relação com as pessoas envolvidas na atividade turística do destino, chegando a ser mencionada a falta de contato. Em alguns casos, chegam a falar, mas quando é uma questão considerada negativa, por exemplo, a pobreza do lugar, tida como estorvo. Citou-se, no entanto, que os viajantes mais instruídos, ou seja, com mais educação formal e que costumam viajar com mais frequência, estes sim, relatam suas impressões acerca da população local, mais especificamente se interessam em conhecer sobre a cultura, considerada como parte da experiência de viajar.

Nas informações coletadas nesta pesquisa, 70\% dos entrevistados declararam que os turistas, ao voltarem de viagem, restringem os seus comentários sobre a qualidade dos serviços prestados, não mencionando o contato com as pessoas.

O grupo de respostas analisadas a seguir trata da relação, ou da proximidade, entre as agências de viagens e os lugares de destino. Buscou analisar se a intermediação da operadora, conforme o canal de distribuição no turismo, controla as relações entre as partes. Considerando a abrangência da autonomia que 
PELARIM, J.G. \& CALVENTE, M.C.M.H. O papel das redes criadas pelas...

possui cada representante do canal de distribuição do turismo, evidencia-se que o contato com os prestadores dos serviços no destino é feito pelas operadoras de turismo em dois terços dos casos, portanto de maneira majoritária, mas em um terço entram também em contato direto para acelerar a solução de pequenos problemas. Um dos entrevistados proprietário de uma agência que há 12 anos organiza todos os anos viagens de pesca para Itacorá, no Paraguai, afirma: "O vínculo formado humaniza o atendimento e a atenção dos prestadores dos serviços".

Sobre o tratamento dispensado ao turista pelos envolvidos locais, perguntou-se se os entrevistados entendem ter uma relação de influência da cultura na prestação dos serviços. Neste aspecto, uma das entrevistadas é categórica e afirma que as redes esfriam as relações, referindo-se as grandes empresas, em especial redes hoteleiras que são fielmente padronizadas. Os serviços prestados por estas empresas seguem normas que são aplicadas em suas unidades, independente do país em que esta esteja localizada, ou seja, um exemplo seriam os hotéis Ibis, da rede Accor, fiéis ao redor do mundo na oferta dos mesmos tipos de serviços.

Existe uma tendência em se padronizar os serviços. Redes hoteleiras oferecem o mesmo padrão, inclusive com padronização na arquitetura e mobiliário em diferentes pontos do mundo. Como não acreditar que exista uma tendência em se seguir um modelo? A formação de um território está atrelada de modo simultâneo a atributos essenciais no que tange a apropriação, a dominação, a relação de poder, a identidade simbólico-cultural, a mudanças (descontinuidades) e a permanências (continuidades) e, sobretudo as redes de circulação, de comunicação e a condição natural inerente ao ser humano enquanto ser genérico, biológico e social (SAQUET, 2009).

Sabe-se que o turismo é uma atividade capaz de realizar alterações territoriais, dada a sua abrangência econômica, social e cultural, sendo, conforme ressalta Coriolano (2006, p. 368), capaz de reproduzir a organização desigual e combinada tão presente em territórios capitalistas, porém estabelecido de acordo com as 
PELARIM, J.G. \& CALVENTE, M.C.M.H. O papel das redes criadas pelas...

particularidades de cada cultura e seus modos de produção. Para a autora: "O turismo, para se reproduzir, segue a lógica do capital, quando poucos se apropriam dos espaços e dos recursos neles contidos apresentando-os como atrativos transformados em mercadorias".

Os entrevistados demonstram em maior parte acreditar que não há uma preocupação direta com a população do local, em suas falas apreendeu-se afirmativas que apontam o interesse das empresas pelo lucro, acima de qualquer coisa. No caso de respostas afirmativas, os exemplos não eram muito concretos, porém lembraram-se de lugares onde o Estado exercia um papel importante de integrador da população local.

Há que se considerar, no entanto, a formação de alguns territórios de resistência. Para saber a apreensão que tem os agentes de viagens sobre este tema, perguntou-se sobre o entendimento que têm a respeito do turismo com base local. A maioria dos entrevistados declarou que não conhecia a expressão, mas um trouxe um relato interessante: seus clientes, ou, como costuma chamá-los, amigos, uma vez que muitos viajam com ele desde o início de suas atividades, preparam-se ao longo do ano para levarem, por exemplo, roupas e brinquedos para as crianças da vila, já que existe uma integração entre eles que gera nos viajantes uma preocupação com as necessidades da população; fazem questão de contratar pessoas do local, assim como deixam para comprar alimentos e bebidas na própria vila que os recebe, a fim de movimentar o comércio.

Coriolano (2006, p. 368) entende que a produção do turismo pode dar-se de diversas formas, residindo neste ponto a riqueza da atividade. Para a autora, este fenômeno: "Ele é, a um só tempo, o lugar de estratégias do capital e das resistências do cotidiano para os habitantes [...]". Segundo Gallero (2001, p. 37) faz-se preciso a atuação por parte do Estado em direcionar o desenvolvimento da atividade turística:

El sistema turístico por país o por región debe ser encarado por el o los estados apuntando a la formación de pequeñas y 
PELARIM, J.G. \& CALVENTE, M.C.M.H. O papel das redes criadas pelas...

medianas empresas y a la orientación técnica [...] Estimular la formación de agrupamientos de las comunidades locales dedicadas a alojamientos familiares, campings, cabañas, restaurantes de comida típicas, recorridos en contacto con la naturaleza y los valores históricos del lugar.

Sobretudo Coriolano (2006, p. 373) alerta ao fato do turismo ser uma entre tantas outras atividades que respondem à lógica capitalista "[...] não é maldição nem benção, é resultado das práticas políticas dos discursos hegemônicos e dos de resistência [...]", ressalta a autora, concluindo:

Obter sucesso no nível comunitário com o turismo não significa desconhecer a presença do Estado ou da mundialização do capital. [...] implica, contudo, em redirecionar a política estatal para os interesses das economias populares [...] O turismo comunitário é uma estratégia de sobrevivência, e de entrada daqueles de menores condições econômicas na cadeia produtiva do turismo, uma forma de turismo que pensa o lugar, a conservação ambiental e ressignifica a cultural.

De modo geral, pode-se apreender que a forma como o turismo é entendido pelos entrevistados mantém a lógica ditada pelas empresas hegemônicas do turismo, sendo poucos os casos de contraposição, como o transcrito na citação.

\section{Considerações finais}

A visão abrangente da Geografia é capaz de contemplar diversos aspectos que envolvem a atividade turística, sendo a contribuição geográfica à análise deste fenômeno inquestionável. Esta pesquisa, em específico, estudou o papel das operadoras de turismo, via agências de viagens, no processo de turistificação que ocorre no território brasileiro, tendo como embasamento teórico o conceito de território-rede e utilizando-se de aplicação de questionários em empresas do município de Londrina para coleta de dados. 
PELARIM, J.G. \& CALVENTE, M.C.M.H. O papel das redes criadas pelas...

Entre os conceitos-chave da Geografia destacou-se o conceito de território e correlatos, que seriam aqueles que têm em sua base ligação conceitual com este. A abordagem conceitual de uma pesquisa científica é de suma importância, exercendo o papel de alicerce, ponto de partida que posteriormente, com o andamento da parte empírica, pode ser confirmado ou questionado.

O processo de turistificação, conforme entendido na sociedade contemporânea, é permeado da visão capitalista de reprodução máxima. Cabe salientar a necessidade de estudos que busquem aprofundamento das relações de apropriação destes espaços pelos agentes produtores da atividade. No Brasil, verificase que os espaços têm sido, via de regra, turistificados segundo os interesses dos agentes de mercado que, ao identificarem oportunidades de investimentos, e dado seu poder de dominação financeira, terminam por sobrepor aos outros agentes sociais envolvidos à sua lógica.

Puderam-se analisar por meio de questionários aplicados aos agentes de viagens suas apreensões acerca das operadoras de turismo que atuam no mercado e suas relações com a composição dos espaços turísticos, assim como as relações dos turistas com os lugares de destino. Alcançou-se que a relação estabelecida entre o viajante e a comunidade local é ínfima, não sendo comum estabelecer-se um envolvimento com o cotidiano do lugar ou, melhor dizendo, as atividades dos turistas restringem-se ao consumo dos itens que compõem o seu pacote de viagem. Relatouse ser ainda incipiente o movimento daqueles que veem a alteridade inclusive como parte integrante da atividade turística, completando e enriquecendo-a; entre os agentes de viagens entrevistados, citou-se que apenas uma pequena parcela de viajantes tem esta visão de integrar a viagem com os atores sociais que fazem parte da cultura local. Estes turistas seriam parte de um grupo com nível de educação formal privilegiado.

Um dado interessante diz respeito à escolha dos operadores com os quais os agentes trabalham. Ao contrário do que trazia a literatura acerca da hegemonia das grandes operadoras de turismo, 
PELARIM, J.G. \& CALVENTE, M.C.M.H. O papel das redes criadas pelas...

a realidade londrinense contrapôs esta noção: entre as três operadoras mais citadas pelos agentes, duas são da região. Uma das operadoras, originária de uma consolidada agência de viagens que atua na cidade de Londrina há mais de 25 anos, com ampla experiência no mercado turístico e, em particular, nas características do mercado local, foi apontada na pesquisa como referência em termos de qualidade de atendimento, de prestação de serviços e de preço. A outra, com história similar, porém com origem na cidade de Foz do Iguaçu, tem uma base de atendimento em Londrina com o propósito de cumprir o que considera ser o objetivo da empresa: excelência no atendimento ao agente de viagens.

Segundo os agentes entrevistados, isto ocorre em virtude da prioridade que se dá à proximidade com o fornecedor, fato este que, segundo eles, humaniza as relações, sem que se perca no quesito preço, dado que existe uma competitividade entre as empresas. Considerou-se que os agentes de viagens que atuam no mercado londrinense realmente avaliam positivamente a questão da proximidade física das operadoras, fato que consolida uma relação mais pessoalizada com o seu fornecedor e, consequentemente, melhor serviço prestado ao seu cliente. Diante destas constatações, pode-se apreender que o mercado nesta cidade esteja resguardado, quem sabe, por certo protecionismo.

Muito embora o fator preço ainda seja encarado como decisivo na escolha dos destinos e, por este motivo, os pacotes de viagens sejam o produto principal, acredita-se que estejam emergindo modificações no comportamento do turista, o qual mais consciente passa a buscar opções menos engessadas e mais humanizadas de se conhecer os lugares. $\mathrm{O}$ maior fluxo de viagens comercializadas com base nas agências de viagens é de pacotes montados pelas operadoras de turismo, que conforme constatado na pesquisa, têm por objetivo nítido atingir diretamente o consumidor final.

Espera-se que esta pesquisa traga uma contribuição, ainda que limitada, à compreensão do dinamismo, tão característico nos 
PELARIM, J.G. \& CALVENTE, M.C.M.H. O papel das redes criadas pelas...

dias atuais, do turismo como uma entre as diversas atividades da sociedade moderna que geram movimentos socioeconômicos. Pôde-se constatar que embora o mercado do turismo em Londrina esteja integrado ao movimento do mercado nacional, preserva características particulares.

\section{Referências bibliogfráficas}

ABAV - Associação Brasileira de Agência de Viagens. 50 anos de história, lutas e vitória. 2004. Disponível em: <http:// www.abav.com.br/default.aspx>. Acesso em: 21 mar. 2013.

A B T Operadora. Disponível em: <http:// www.abtoperadora.com.br/Empresa>. Acesso em: 25 fev. 2013.

ATHENIENSE, L. R. A responsabilidade jurídica das agências de viagem. Belo Horizonte: Del Rey, 2004.

BENI, M. C. Análise estrutural do turismo. $5^{\mathrm{a}}$ ed. São Paulo: SENAC, 2001.

BRASIL. Decreto $n^{\circ} 84.934$, de 21 de julho de 1980. Disponível em: <http:/www6.senado.gov.br/legislacao/ListaNormas.action?

numero $=84934 \&$ tipo_norma $=$ DEC $\&$ data $=19800721 \&$ link $=\mathrm{s}>$. Acesso em: 13 nov. $20 \overline{1} 2$.

. Segmentação do turismo e o mercado. Brasília: Ministério do Turismo, 2010. Disponível em: <http://portal.cnm.org.br/sites/ 5700/5770/28122010_Segmentacao_do_Turismo_e_o_Mercado.pd f>. Acesso em: 06 nov. 2012.

CADASTUR. Disponível em: <http:// www.cadastur.turismo.gov.br/cadastur/index.action $>$. Acesso em: 31 out. 2012. 
PELARIM, J.G. \& CALVENTE, M.C.M.H. O papel das redes criadas pelas...

CORIOLANO, L. N. Turismo: prática social de apropriação e de dominação de territórios. In: LEMOS, A. I. G.; ARROYO, M.; SILVEIRA, M. L. América Latina: cidade, campo e turismo. São Paulo. CLASCO, 2006. pp. 367-378. Disponível em: <http:// bibliotecavirtual.clacso.org.ar/clacso/coediciones/ 20100729093433/21>. Acesso em: 09 mar. 2013.

CVC - Viagens. Disponível em: <http://www.cvc.com.br/ institucional/nossa-historia.aspx>. Acesso em: 25 fev 2013.

DIAS, L. C. Redes: emergência e organização. In: CASTRO, I. E. de; GOMES, P. C. da C.; CORRÊA, R. L. (Org.). Geografia: conceitos e temas. Rio de Janeiro: Bertrand Brasil, 1995. p. 141-162.

FRT Operadora de turismo. Disponível em: <http:// www.frtoperadora.com/pagina.php?pagina $=$ quem-somos $>$. Acesso em: 25 fev. 2013.

GALLERO, A. L. El impacto de la globalización sobre el turismo. In: RODRIGUES, A. B. (Org.). Turismo e geografia: reflexões teóricas e enfoques regionais. $3^{\mathrm{a}}$ ed. São Paulo: Hucitec, 2001. pp. 33-39.

HARVEY, D. Condição pós-moderna - Uma pesquisa sobre as origens da mudança cultural. 11 ${ }^{\mathrm{a}}$ ed. São Paulo: Edições Loyola, 1992.

REJOWSKI, M. Agência de viagens. In: ANSARAH, M. G. dos R. (Org.). Turismo como aprender, como ensinar. $3^{\text {a }}$ ed. São Paulo: SENAC, 2004. v. 2. p. 37-64.

ROCHA, A. M. O turismo e a reconstrução de territórios do espetáculo na metrópole Fortaleza. Dissertação (Mestrado em Geografia), Universidade Estadual do Ceará, Fortaleza, 2006. 
PELARIM, J.G. \& CALVENTE, M.C.M.H. O papel das redes criadas pelas...

SAQUET, M. A. Por uma abordagem territorial. In:

SPOSITO, E. S. (Org.). Territórios e territorialidades: teorias processos e conflitos. São Paulo: Expressão Popular: UNESP, 2009. pp. 73-94.

URRY, J. $O$ olhar do turista: lazer e viagens nas sociedades contemporâneas. São Paulo: Studio Nobel: SESC, 1996.

ZAGHENI, E. S. da S.; LUNA, M. M. M. Canais de distribuição do turismo e as tecnologias de informação: um panorama da realidade nacional. Revista Produção Online. Florianópolis, v. 11, n. 2, abr./jun., 2011. p. 476-502. Disponível em: <http:// producaoonline.org.br/rpo>. Acesso em: 21 feb. 2013

Recebido em maio de 2014 Aceito em outubro de 2014 